\title{
Assessment of USDA-NRCS rangeland conservation programs: recommendation for an evidence-based conservation platform
}

\author{
D. D. Briske, ${ }^{1,7}$ B. T. Bestelmeyer, ${ }^{2}$ J. R. Brown, ${ }^{3}$ M. W. Brunson, ${ }^{4}$ T. L. Thurow,${ }^{5}$ and J. A. Tanaka ${ }^{6}$ \\ ${ }^{1}$ Department of Ecosystem Science and Management, Texas A\&M University, 2138 TAMU, College Station, Texas 77843 USA \\ ${ }^{2}$ USDA-ARS, Jornada Experimental Range and Jornada Basin LTER, New Mexico State University, MSC 3JER, \\ P.O. Box 3003, Las Cruces, New Mexico 88003-0003 USA \\ ${ }^{3}$ USDA-NRCS, Jornada Experimental Range, MSC 3JER, P. O. Box 3003, Las Cruces, New Mexico 88003-0003 USA \\ ${ }^{4}$ Department of Environment and Society, Utah State University, 5215 Old Main Hills, Logan, Utah 84322-5212 USA \\ ${ }^{5}$ Department of Ecosystems Science \& Management, University of Wyoming, Agriculture Building 2013, Dept 3354, \\ Laramie, Wyoming 82071 USA \\ ${ }^{6}$ Wyoming Agricultural Experiment Station, University of Wyoming, 1000 E University Avenue, Dept 3354 , \\ Laramie, Wyoming 82071 USA
}

\begin{abstract}
The Conservation Effects Assessment Project (CEAP) was created in response to a request from the Office of Management and Budget that the U.S. Department of Agriculture, Natural Resource Conservation Service (USDA-NRCS) document the societal benefits anticipated to accrue from a major increase in conservation funding authorized by the 2002 Farm Bill. A comprehensive evaluation of the efficacy of rangeland conservation practices cost-shared with private landowners was unable to evaluate conservation benefits because outcomes were seldom documented. Four interrelated suppositions are presented to examine the causes underlying minimal documentation of conservations outcomes. These suppositions are (1) the benefits of conservation practices are considered a certainty so that documentation in not required, (2) there is minimal knowledge exchange between the USDA-NRCS and research organizations, (3) and a paucity of conservation-relevant science, as well as (4) inadequate technical support for land owners following implementation of conservation practices. We then follow with recommendations to overcome potential barriers to documentation of conservation outcomes identified for each supposition. Collectively, this assessment indicates that the existing conservation practice standards are insufficient to effectively administer large conservation investments on rangelands and that modification of these standards alone will not achieve the goals explicitly stated by CEAP. We recommend that USDA-NRCS modify its conservation programs around a more comprehensive and integrative platform that is capable of implementing evidence-based conservation. Collaborative monitoring organized around landowner-agency-scientist partnerships would represent the focal point of a Conservation Program Assessment Network (CPAN). The primary network objective would be to establish missing information feedback loops between conservation practices and their agricultural and environmental outcomes to promote learning, adaptive management, and innovation. Network information would be archived and made available to guide other, related conservation programs in relevant ecoregions. Restructuring conservation programs as we recommend would (1) provide site specific information, learning, and accountability that has been requested by CEAP and (2) further advance balanced delivery of agricultural production and environmental quality goals.
\end{abstract}

Key words: knowledge coproduction; policy-relevant science; rangeland stewardship; resilience-based management; science-policy gap.

\section{INTRODUCTION}

The renowned conservationist Aldo Leopold stated that "conservation will ultimately boil down to rewarding the private landowner who conserves the public interest" (Leopold 1934). This was written shortly following authorization of the first Agricultural Adjustment Act (predecessor of subsequent Farm Bills) in 1933, although the primary emphasis was soil and water conservation to

Manuscript received 13 February 2016; revised 24 June 2016; accepted 27 July 2016. Corresponding Editor: Erik J. Nelson.

${ }^{7}$ E-mail: dbriske@tamu.edu increase agricultural production (Cain and Lovejoy 2004). However, Farm Bill legislation has been striving for greater balance in provisioning agricultural commodities (private goods) and environmental quality (public goods) for the past three decades. This represents an important advance for natural resource conservation on private lands but is far from complete and tension exists among proponents of these two interrelated goals. The primary mechanisms for incentivizing conservation on privately owned lands in the USA are cost-share payments to implement specific conservation practices (USDA Natural Resource Conservation Service [NRCS] 
TABLE 1. Extent and cost $(\$)$ of conservation practices implemented by NRCS cost-share programs on U.S. rangelands during 2004-2012.

\begin{tabular}{lrr}
\hline \hline Conservation practice & US\$ invested & Extent (ha) \\
\hline Prescribed grazing & $54,721,000$ & $58,026,000$ \\
Prescribed burning & $4,350,000$ & 597,000 \\
Brush management & $243,443,000$ & $2,715,000$ \\
Range planting & $24,576,000$ & 613,000 \\
Riparian herbaceous cover & $72,062,000$ & 23,000 \\
Upland wildlife habitat & $10,515,000$ & $32,761,000$ \\
$\quad$ management & $337,680,000$ & $94,735,000$ \\
\hline
\end{tabular}

Notes: Values represent an aggregate of 10 unique conservation programs, of which EQIP is that largest, that were derived from the USDA-NRCS Resource Inventory Division, PROTRACTS database (public domain http://prohome.NRCS.USDA.GOV/). Data was not available for the invasive plant management practice.

Conservation Practices) and to provide technical assistance to landowners. Seven major practices had been implemented on $\sim 95,000$ ha (188 million total ha) of privately owned rangeland at a cost of $\sim$ US $\$ 338,000$ during the period 2004-2011 (Table 1). Although these programs involve multiple federal agencies, the Natural Resources Conservation Service (NRCS) has consistently held the responsibility for technical support and assistance. We use the term "conservation practice" to describe the various actions recommended by NRCS for implementation by land owners to promote conservation outcomes (Table 1) and conservation practice standards to describe the rationale for when a specific practice is to be applied, eligibility requirements, cost-share procedures, and compliance requirements. Conservation programs provide the overarching guidance for both conservation practices and their standards by describing administrative goals, authorization procedures, and funding allocations.

A brief history of USDA Conservation Programs is presented to describe the original intent and procedures through which these funds are authorized, increasing emphasis on environmental quality goals and the events contributing to the assessment of conservation programs discussed here. The initial Farm Bill (Agricultural Adjustment Act) was authorized by Congress during the Franklin Delano Roosevelt administration as part of the New Deal in 1933 to provide financial and food assistance to farmers whose livelihoods had been devastated by the Great Depression and severe drought in the 1930s (Cain and Lovejoy 2004). The Farm Bill authorized in 1938 had a more permanent status and subsequent farm bills continued to emphasize agricultural production and food security goals for several decades. Explicit reference to environmental goals and linking landowner eligibility to conservation compliance first appeared in the 1985 Farm Bill (Food Security Act) in the form of the Conservation Reserve Program and sod- and swampbuster programs. Over the next decade, conservation funding in Environmental Quality Incentive Program (EQIP), the primary program funding conservation practices, increased from US\$200 million in 1996 to US\$1.3 billion in the 2002 Farm Bill (Farm Security and Rural Investment Act) with the expressed goal of maximizing the environmental benefits of conservation funding. In response to this large increase in conservation funding, the Office of Management and Budget requested that USDA-NRCS document the societal benefits that were anticipated to accrue from this large increase in conservation funding.

The Conservation Effects Assessment Project (CEAP) was created by multiple agencies within the USDA to address this request with the expressed goal "to improve efficacy of conservation practices and programs by quantifying conservation benefits and providing the science and education base needed to enrich conservation planning, implementation, management decisions, and policy" (Duriancik et al. 2008; project data available online). ${ }^{8}$ CEAP synthesis teams were established for croplands, wetlands, wildlife, and grazing lands; the latter was divided into pastureland and rangeland, and separate synthesizes were completed for each. An unprecedented assessment of rangeland conservation practices was conducted 2007-2011 as part of this broader effort (Briske 2011). A team of 40 U.S. scientists, interacting with 30 NRCS partners, was assembled to assess the effectiveness of seven major conservation practices: prescribed grazing, prescribed burning, brush management, range planting, riparian herbaceous cover, upland wildlife habitat management, and invasive plant management. These are the dominant conservation practices on rangelands, and they have been implemented for decades, both with and without federal cost-share funding. The CEAP synthesis team treated the stated goals of these conservation practice standards as hypotheses that were tested with relevant published experimental data to develop the rangeland CEAP synthesis (Briske 2011) that is evaluated in this paper. A summary of the benefits and limitations identified by the rangeland CEAP assessment for each of the seven management practices is presented in Box 1 .

The rangeland CEAP Synthesis was unable to document conservation benefits that had accrued from previously implemented conservation practices. This was a direct consequence of the absence of established protocols to account for the outcomes of conservation investments on rangelands. In the absence of greater accountability for conservation programs, Smith (2006) has indicated that these investments merely represent payments for environmentally friendly agriculture. This lack of accountability jeopardizes continuation of investments in practices that may be achieving conservation benefits that are undetected, and it minimizes the potential for innovation and learning to increase subsequent conservation efficacy.

The scope of the CEAP synthesis excluded an evaluation of the broader conservation programs and policies

\footnotetext{
${ }^{8}$ http://www.nrcs.usda.gov/wps/portal/nrcs/main/national/ technical/nra/ceap/
} 
Box 1. Summary of the benefits and deficiencies identified by the rangeland CEAP synthesis for each of the seven conservation practices evaluated (Briske 2011).

\section{Prescribed GraZing}

Benefits Grazing management guidelines are broadly supported by experimental data; stocking rate is a key management variable that influences numerous conservation outcomes.

Deficiencies Effective management is more critical to conservation success than is a specific method of grazing management; guidelines and incentives promoting adoption of, and skill sets for, adaptive management are required to optimize conservation outcomes.

\section{Prescribed Burning}

Benefits Fire can effectively manage wood plant cover and in cases where herbaceous vegetation is negatively affected by fire, these effects persist for only $2-3 \mathrm{yr}$.

Deficiencies Current knowledge of fire behavior does not provide sufficient guidance to support the agencies purposes for this practice; fire return intervals and landscape position receive minimal attention; conservation benefits will be optimized when fire regimes approximate those that historically occurred.

\section{Brush Management}

Benefits This practice is critical for maintenance of grassland and savanna systems; positive grass responses occur to woody plant removal within $2 \mathrm{yr}$ post-treatment and peak at $5 \mathrm{yr}$ post-treatment.

Deficiencies Overgeneralizations of brush management recommendations across ecoregions has limited the success of this management practice; few experimental investigations indicate that this practice increases water yield; greater emphasis needs to be focused on the type, timing, and sequencing of brush management practices to increase conservation success.

\section{Range Planting}

Benefits Experimental evidence broadly supports recommendations for this management practice, but successful stand establishment is very limited and highly variable.

Deficiency The success of various planting techniques, rather than on conservation benefits realized from planting, have received the greatest attention; given the limited success of planting implementation needs to be weighed against the conservations risks of not planting and relying on natural regeneration.

\section{Riparian Herbaceous Cover}

Benefit Control of season, intensity, and duration of livestock grazing promotes recovery of riparian systems; water developments, location of animal supplements, and herding are most effective in minimizing time livestock spend in these systems; these practices can attenuate water-borne pollutants during floods.

Deficiency The effort made by livestock managers, rather than specific practices per se, are directly related to riparian health.

The effect of grazing management on riparian systems requires rigorous investigation, especially the ecological processes supporting these outcomes.

\section{Wildlife Habitat Management}

Benefits Very few of the agency management practices focused on upland wildlife habitat have been evaluated experimentally. Research has primarily emphasized livestock-wildlife interactions, and most investigations report more negative than positive impacts to wildlife.

DeficiencyPractices designed to support groups of wildlife species are often ineffective because of divergent species specific needs; target species are benefited while associated species may be detrimentally effected.

\section{Herbaceous Weed Control}

Benefits This practice was only minimally developed at the time of the CEAP synthesis. It was requested that synthesis team members develop a more complete conservation practice standard for this rangeland challenge.

Deficiencies The long-term risk of failure is high with existing practices even when an invasive species has initially been controlled. Greater emphasis needs to be placed on maintenance and restoration of ecosystem function to maximize resource utilization as a preventive strategy to reduce colonization and spread of invasive species. 
associated with the seven conservation practices that had been identified. In retrospect, this contributed to a narrow framing of the CEAP synthesis that greatly diminished its value relative to the intended goals of CEAP. As currently structured, these standards are inconsistently coupled to available science, relevant USDA databases, and most importantly, knowledge of environmental outcomes of conservation practices. For example, critical practice specifications that incorporate local edaphic, climatic, and ecological considerations into practice selection, placement, and implementation are currently not included in the practice standards and are left to local, case by case determinations. Therefore, modification of conservation practice standards alone is insufficient to improve the efficacy, cost-effectiveness, and accountability of conservation investments (Smith 2006). These limitations are further magnified when region specific conservation priorities are identified in the enabling legislation (e.g., Sage Grouse, Lesser Prairie Chicken) because the capacity does not exist to assess specific species responses over appropriate spatio-temporal scales. Collectively, these limitations make a compelling case for the redesign of USDA-NRCS conservation programs toward a more comprehensive and integrated platform that has the capacity to implement evidence-based conservation to increase both the efficacy and cost-effectiveness of conservation investments (Duke et al. 2013).

The major goal of this paper is to examine the underlying causes contributing to minimal documentation of the outcomes of well-established, federally funded conservation practices on U.S. rangelands. Specific objectives are to (1) evaluate four broad suppositions regarding the minimal documentation of conservation outcomes, (2) provide recommendations to overcome potential barriers to conservation documentation identified in these suppositions, and (3) to introduce a platform capable of providing evidence-based conservation to increase the efficacy and accountability of rangeland conservation investments. Within the context of natural resource management, knowledge can be envisioned to be bounded by scientific and local sources (Roux et al. 2006, Raymond et al. 2010). Scientific knowledge is derived from organized, systematic inquiry and aims for generalizable objectivity, explicitness, and transferability across contexts. Local or traditional knowledge is developed through experiences of resource users and tends to be subjective, holistic, place-based, and problem-oriented.

\section{Assessment Suppositions And Recommendations}

Four interrelated suppositions are presented to examine the underlying causes contributing to minimal documentation of conservations outcomes. These suppositions are (1) the benefits of conservation practices are considered a certainty so that documentation is unnecessary, (2) there is minimalknowledgeexchange between the USDA-NRCS and research organizations, (3) a paucity of conservationrelevant science, and (4) inadequate technical support for land owners following implementation of conservation practices. We describe them as suppositions because the reasons that the NRCS, and more broadly the rangeland profession, have failed to monitor conservation outcomes are likely varied, developed early in the agencies' history, and little evidence was found to directly substantiate these interpretations. We then follow with recommendations to overcome potential barriers associated with these suppositions to promote greater efficacy and accountability of conservation programs.

This assessment was derived by informal, post-hoc, qualitative investigation of the unprecedented evaluation of seven major rangeland conservation practices described in the Rangeland CEAP Synthesis (Briske 2011). Information derived from formal and informal discussions among assessment team members and NRCS personnel, as well as insights obtained from inspection of agency procedures, actions, and outcomes were also used. This assessment was collaboratively developed among the six authors of this paper, each of whom directly contributed to the original synthesis, over a 2-yr period following its publication in 2011. It differs from that of the rangeland CEAP synthesis by emphasizing the broader conservation programs and policies that were considered to be beyond the bounds of the original effort that focused exclusively on conservation practices. More rigorous evaluation of the suppositions describing the limited assessment of conservation outcomes, with a variety of social science methods, may yield further insights into their origins and persistence and the organizational changes required to overcome them.

\section{Benefits of Conservation Practices are Considered a Certainty}

\section{Limitations}

The efficacy of major rangeland conservation practices appears to be considered self-evident, based on their long tradition of use and perceived, albeit not systematically quantified, benefits. This is consistent with certainty and predictability inherent to centralized management decision-making (Holling and Meffe 1996). The absence of formal conservation monitoring that directly linked conservation practices with their outcomes has inhibited development of information feedback loops that would have supported learning, experimentation, and innovation, and this may have contributed to limited knowledge exchange. In the absence of information feedbacks to document conservation effectiveness, metrics describing implementation of the conservation program, land area treated, number of contracts written, amount of funds allocated, and types of management practices applied, were presented as surrogates (Ferraro and Pattanayak 2006, Gibbons et al. 2011). The marginal success and failure of previous monitoring programs that have been ascribed to insufficient funding, unclear objectives, inadequate sample designs, and lack of analytical resources may 
have contributed to the perception that the benefits of monitoring do not offset the costs (McDonald-Madden et al. 2010, Lindenmayer et al. 2013). In addition, the metrics that motivate scientists, e.g., funding, prestige, and publication, emphasize the creation of new knowledge, rather than the confirmation of existing science in management applications (Neugarten et al. 2011).

The inability to explicitly link conservation outcomes to individual practices identified by the CEAP synthesis corroborates the conclusions of Ferraro and Pattanayak (2006) that the emphasis placed on inputs in conservation investments must be appropriately balanced with the outcomes that have been realized from these investments. However, the development of explicit linkages between inputs and outputs is challenging because practices frequently have multiple interacting components, e.g., proper grazing management involves meeting stocking rate, animal distribution, and season-of-use objectives, and practices are generally applied to specific sites, while conservation outcomes are often evaluated at much larger scales. In addition, these linkages are most easily developed when conservation outcomes are simple and direct as in the case of soil erosion and when practice inputs are readily documented as is the case for tillage frequency and seasonality, but these linkages are often more difficult to establish in rangeland systems. Consequently, conservation planning developed for arable lands is not directly transferable to rangelands (Chan et al. 2006).

\section{Recommendation}

Rangeland conservation outcomes may be most effectively determined by selective, systematic monitoring of both production and environmental quality outcomes designed to detect landscape-level consequences. This will require collaborative partnerships and knowledge exchange among landowners, agency personnel, and scientists (Fernandez-Gimenez et al. 2005, Head 2015). Considerable knowledge exists regarding protocols for rangeland monitoring (Herrick et al. 2005, 2006), but commitment and incentives are required to routinely fund and implement them and to efficiently incorporate the resulting information in subsequent conservation decision-making (Ferraro and Pattanayak 2006, Karl et al. 2012). This will require development of a more comprehensive conservation framework that can coordinate monitoring programs and archive, manage, interpret, and exchange this information among relevant organizations and stakeholders (Cundill and Fabricius 2009, Karl et al. 2012). The most direct approach to funding collaborative monitoring programs would be to make them a mandatory component of conservation programs supported by Farm Bill appropriations ensuring that all conservation programs have an assessment budget (Batie 2009). The benefits ascribed to specific practices and conservation programs more broadly will continue to be vetted in the political arena until evidenced-based assessments are conducted to determine their effectiveness and identify the social and biophysical conditions that influence their effectiveness (Neugarten et al. 2011, Duke et al. 2013).

The rangeland CEAP synthesis recommended that a two tiered approach be adopted for monitoring (Briske 2011). The first tier represents informal monitoring that is frequently conducted by landowners over large areas through qualitative visual appraisals of numerous indicators (e.g., forage availability, invasive species, erosion) to provide real-time assessments that inform management decisions (Woods and Ruyle 2015). The potential value of management knowledge derived from informal monitoring was recognized by both ranchers and representatives of several agencies in Arizona (Fernandez-Gimenez et al. 2005). However, this knowledge is context-specific and its application may be constrained by barriers associated with economics and social norms (Knapp and Fernandez-Gimenez 2009). The second tier emphasizes formal monitoring, which is systematically conducted less frequently at specific sites by agency professionals and researchers to produce empirical evidence of the benefits of conservation practices. We envision informal monitoring to be supported by the increased availability and distribution of technical guides and tools to landowners and formal monitoring to be conducted by the collaborative partnerships described in the recommendations section (Fig. 1).

\section{Minimal Knowledge Exchange}

\section{Limitation}

The CEAP synthesis was designed to evaluate the effectiveness of knowledge developed and implemented by the USDA-NRCS conservation programs, and the broader rangeland profession, with relevant scientific knowledge. In retrospect, this represents an impossible challenge because of the complex and poorly understood epistemological considerations involved in comparing and sharing knowledge sources (Raymond et al. 2010, Bohensky and Maru 2011). An optimal approach to integrating local and scientific knowledge that does not dilute the core identity of either source has yet to be developed (Raymond et al. 2010). Not surprisingly, attempts to evaluate local knowledge with scientific knowledge within CEAP were ineffective and largely met with "tolerant ambivalence" as described by MacMynowski (2007), and a palpable tension often existed between representatives of the two knowledge sources. Fleischman and Briske (2016) have proposed that natural resource management agencies, including the NRCS, may make decisions on basis of professional ecological knowledge, rather than local or scientific knowledge per se. This knowledge source is founded upon codification of broad ecological principles, but not necessarily scientific evidence, to legitimize agency programs, support operational efficiency, and encourage user compliance. 


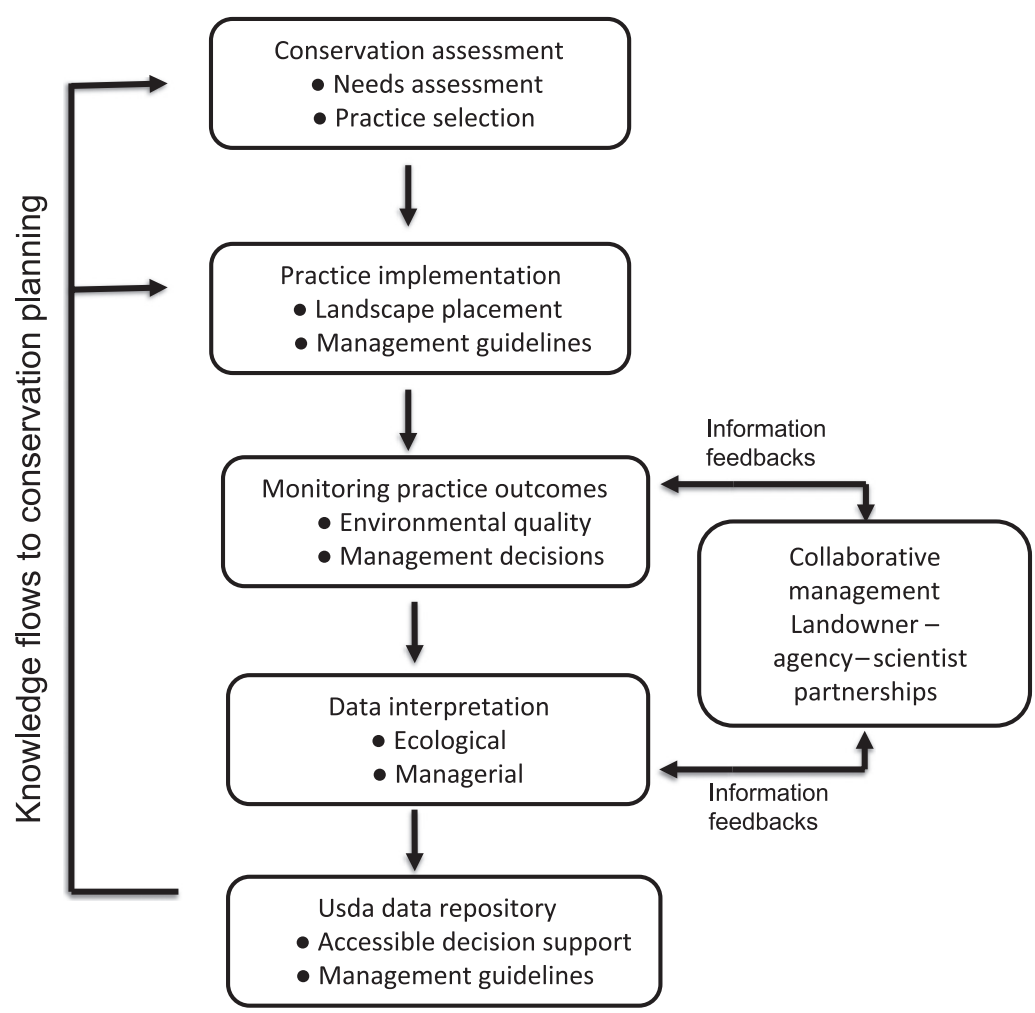

FIG. 1. Concept diagram of a conservation program assessment network designed to implement evidence-based conservation on rangelands. A collaborative partnership of landowners, agency personnel, and scientists would design, implement, and monitor agricultural and environmental outcomes of major conservation practices within representative ecoregions. This co-produced knowledge would feedback to inform the selection, placement, and management of conservation practices, and populate an accessible data repository that would provide relevant information to support related conservation planning in specific ecoregions.

Professional ecological knowledge may be misinterpreted as either scientific or local knowledge, and it may inhibit knowledge exchange among these two sources.

The absence of a valid procedure to assess and integrate science and local knowledge presents a major barrier to development of science-based conservation programs. Organizational representatives often hold their knowledge in highest regard while being much less familiar with other sources, which contributes to the tendency to dismiss other knowledge sources, rather than to learn from them (Holling and Meffe 1996, Roux et al. 2006). Natural resource managers claim that scientific knowledge is inadequate for their needs, and scientists claim that valuable scientific knowledge is not being incorporated into management and policy recommendations. Both claims are partially correct, but neither assumes responsibility for minimal knowledge exchange among scientific organizations and management agencies that has collectively contributed to the paucity of conservation-relevant science (Roux et al. 2006, Weichselgartner and Kasperson 2010). In spite of the nearly four year duration of the rangeland CEAP synthesis, no attempt was made to develop persistent procedures to facilitate knowledge exchange or engage in knowledge co-production among NRCS and research organizations, indicating that substantial barriers exist to the realization of this outcome.

\section{Recommendation}

Minimal and inconsistent knowledge exchange among landowners, agency personnel, and scientists presents a compelling case for development of greater formal and informal partnerships among these groups (Knapp and Fernandez-Gimenez 2009, Cook et al. 2013, Roche et al. 2015). The most expedient approach to increasing knowledge exchange between the producers and users of knowledge may be development of greater bridging capacity within existing technology transfer organizations, such as Cooperative Extension and USDA-NRCS (Roux et al. 2006, Dilling and Lemos 2011). Federal management agencies can promote knowledge exchange and coproduction by explicitly involving science and scientists in conservation planning and policy development, and by constructing mechanisms to support knowledge exchange (Pouyat et al. 2010, Cook et al. 2013). Scientific organizations can engage agency personnel in the research process, minimize the transactions costs of engagement, and value products that emerge from outreach scholarship, if they are to achieve greater relevance in framing natural resource 
conservation (Lawton 2007, Whitmer et al. 2010). Knowledge exchange will benefit from clearly established legitimacy and incentives, especially greater recognition of the value of co-produced knowledge (Head 2015).

\section{Paucity of Conservation-Relevant Science}

\section{Limitations}

The CEAP synthesis found that only a small portion of the scientific evidence complied directly addressed the objectives of the conservation practice standards (Briske 2011). For example, prescribed grazing research only addressed a few select ecological outcomes, but many components of environmental quality and the decisionmaking processes of managers were often overlooked; prescribed burning research was often conducted at very small scales and failed to account for fire return intervals and landscape position; and rangeland seeding investigations exclusively emphasized seeding techniques, rather than conservation benefits (see deficiencies in Box 1). This is symptomatic of reductionist science where specific variables and ecological processes are precisely measured, but only seldom are these "pieces of science" packaged in a sufficient context to meaningfully inform conservation programs (Ludwig 2001, Sayre et al. 2012). Science emphasizes precision and repeatability, but it often lacks sufficient context for successful conservation applications because these actions occur within complex adaptive systems characterized by economic, political, and cultural considerations, in addition to substantial environmental variability (Lawton 2007, Head 2015). Consequently, scientists are often more adept at sharing explicit information to advance understanding, rather than in knowledge generation and sharing to promote problem-solving (Roux et al. 2006). Several federal funding agencies, including USDA National Institute for Food and Agriculture, have recognized and addressed the need for greater conservation-relevant science by requiring involvement of various stakeholder groups in some research projects from the outset (Gold et al. 2013).

The paucity of conservation-relevant science may partially be responsible for limited incorporation of scientific knowledge in conservation programs as evidenced by the reliance of ecosystem managers on prior experience or anecdotal evidence (Pullin et al. 2003). This may also partially explain why federal natural resource management agencies often do not use contemporary science to support their programs. For example, the mean age of citations in USDA regulatory impact analyses was 17.3 years, the most dated of the 13 agencies evaluated (Desmarais and Hird 2014). The CEAP synthesis team also observed the use of dated books and government reports, rather than contemporary scientific evidence, to substantiate the agency conservation practices standards. This corroborates the interpretation of Roux et al. (2006) that natural resource management agencies frequently possess a limited capacity for knowledge exchange, adoption of scientific knowledge in this case, and it also represents an important attribute of professional ecological knowledge previously discussed (Fleischman and Briske 2016).

\section{Recommendation}

Knowledge co-production within landowner-agency personnel-scientist partnerships as previously described may represent the most efficient path toward development of greater conservation-relevant science. Knowledge created from monitoring outcomes of conservation practices, especially if collaboratively developed, may contribute to more rapid development of conservation relevant knowledge than more traditional forms of experimental research (Stafford Smith et al. 2007, Cundill and Fabricius 2009). Instances of agreement among science and local knowledge within communities of practice provide highly creditable knowledge for implementation and instances of disagreement provide learning opportunities and hypotheses for further testing (Woods and Ruyle 2015). This provides further justification for greater involvement of agency personnel in identification of priority research questions and establishment of research agendas (Holmes and Clark 2008, Sutherland and Freckleton 2012).

\section{Inadequate Post-implementation Technical Support FOR LAND OWNERS \\ Limitation}

Ecological information represents necessary but insufficient knowledge to assess and manage natural resources because management is strongly influenced by human values, goals, and capabilities (Robinson 2006, Lawton 2007). Similarly, the benefits accrued from conservation practices are in large part a consequence of the effectiveness with which landowners manage them following implementation (Briske et al. 2011). By focusing exclusively on the implementation of conservation practices, a major component of conservation effectiveness is left to the discretion of individual landowners with limited guidance and tools to support practice management. Fairfax and Fortmann (1990) have previously recognized that natural resource agencies often assume that management strategies can be separated from local resource use. The ineffectiveness of this approach lies in the limited relevance and usefulness of knowledge developed in isolation of its place-based consumers (MacMynowski 2007). Agency capacity for field-based conservation planning was greatly reduced by conservation compliance (1985) and the Environmental Quality Incentives Program (2002). Each of these legislative mandates shifted the agency away from objective based planning to determining program eligibility and compliance (NSAC 2014a, b).

Recognition that conservation outcomes are dependent upon post-implementation management as much as they are on appropriate practice selection and placement on the landscape necessitates that landowners be provided 
with ready access to relevant technical information and tools to support post-implementation management. Many management guides and tools currently exist within NRCS, but they are not directly linked to conservation practices standards and other management guides are yet to be developed. For example, conservation practice standards repeatedly emphasize the importance of proper stocking rate, but there is little application of stocking rate calculators that have been developed by university and extension programs (Stocking Rate Calculator; available online) or long-range weather forecasts to support drought planning (U.S. Drought Monitor; available online). ${ }^{9,}{ }^{10}$ An increase in the availability and delivery of technical guidance and tools for landowners would potentially compensate for the reduced conservation planning capacity of NRCS described above by shifting greater responsibility to landowners enrolled in conservation contracts.

\section{Recommendation}

Landowner access and implementation of management guidelines and tools could be incentivized by incorporating them into compliance requirements of cost-share contracts. For example, incremental cost-share payments could require that a select number of management actions be addressed and documented by landowners at each payment period. A lengthening of contract periods is needed to be more consistent with the time required to achieve desired conservations outcomes on rangelands compared to more intensively managed agricultural systems. While many of the assumed conservation benefits in cropland systems can accrue on an annual basis, rangeland conservation goals may require planning horizons that can easily exceed a decade (Bestelmeyer et al. 2011).

\section{RECOMMENDATIONS FOR AN EVIDENCE-BASED Conservation Platform}

The limitations of existing conservation practice standards as outlined previously make a compelling case for modifications of USDA-NRCS conservation programs, standards, and perhaps practices. We recommend development and implementation of a more comprehensive and integrated platform that has the capacity to deliver evidence-based conservation to increase the efficacy, cost-effectiveness, and accountability of conservation investments (Fig. 1). We envision this platform as a Conservation Program Assessment Network (CPAN) that is organized around collaborative monitoring of conservation practices outcomes by landowner-agencyscientist partnerships at representative locations. The primary objective of this network would be to establish

\footnotetext{
${ }^{9}$ https://itunes.apple.com/us/app/stocking-rate-calculator-for/ id 814140174 ? $\mathrm{mt}=8$

${ }^{10} \mathrm{http}: / /$ droughtmonitor.unl.edu/
}

the missing information feedback loops between implementation of conservation practices and their agricultural and environmental outcomes. This will require that participants collaboratively design, implement, and supervise monitoring of major conservation practices on major ecological sites in relevant ecoregions (Cundill and Fabricius 2009). By organizing monitoring at the regional level, based on knowledge exchange informed by local experience, the network can minimize scale mismatches between policy and implementation that presently occur. The resultant monitoring information would be collaboratively assessed and analyzed from the perspective of both agricultural and ecological outcomes to improve the selection and placement of conservation practices and their post-implementation management. Spatially explicit data cannot be archived because it may violate landowner confidentiality agreements, but we envision a regional emphasis to best serve the purposes of CPAN. Although this represents a major undertaking for the agency, it is well justified by the emphasis that has been placed on environmental benefits of conservation and the need for greater accountability of conservation investments by CEAP and recent Farm Bills.

Information derived from collaborative monitoring actions of CPAN would be archived in a data repository that would be accessible to agency personnel to inform subsequent evidence-based conservation assessments within similar ecoregions (Major Land Resource Areas, MLRA as described by NRCS). This information would guide agency personnel in the development of appropriate conservation plans with landowners regarding problem identification, practice selection, placement on the landscape, implementation, and post-implementation management (Fig. 1). A summary of this conservation program information could be incorporated as a specific entry in the ecological site descriptions of the Ecological Site Inventory System (ESIS). The incorporation of conservation planning in an established land management framework would support this process with several major databases, including the national soil survey, vegetation and climate data, and descriptions of known and anticipated ecological dynamics contained in site specific stateand-transition models. This information is necessary to provide the practice specifications that are absent in current conservation practice standards. This network could be integrated within the Long-term Agroecosystem Research (LTAR) Network of USDA that has been created to support transdisciplinary science across resource regions to provide a permanent set of network nodes, in addition to those established cooperatively on private rangelands (USDA LTAR; available online). ${ }^{11}$

Development of collaborative partnerships among federal and university scientists and resource specialists from various federal agencies to operationalize CPAN could follow the procedures that the agency used to

\footnotetext{
${ }^{11}$ http://www.ars.usda.gov/research/programs/programs htm?np_code $=211 \&$ docid $=22480$
} 
establish ESIS in the late 1990s. In this instance, the agency conducted a major programmatic reorganization to replace the traditional procedure of rangeland assessment with state-and-transition models that currently represent the central component of ESIS. The ESIS framework was populated with relevant information from the previous assessment procedure and knowledge of ecological dynamics that was derived by convening workshops with professional land managers and scientists from multiple organizations in various ecoregions. This initial information could be updated and refined as additional conservation monitoring data becomes available via CPAN. The success of this reorganization is evidenced by the signing of a memorandum of agreement by the NRCS, U.S. Forest Service, and the Bureau of Land Management in 2010 stating that ESIS would be used as a standard resource for rangeland assessment (BLM 2010).

We acknowledge that the acquisition and assessment of monitoring data, regardless of its extent and rigor, will not necessarily eliminate all natural resource management controversies. As a case in point, intensive rotational grazing systems are among the most rigorously evaluated rangeland practices, yet some managers, and a few scientists, argue that benefits of this practice may accrue beyond those that have been documented by extensive experimental evidence (Briske et al. 2008). However, these experiments focused exclusively on ecological metrics that were unable to account for the contribution of effective management decisions, and this has been hypothesized to be a major source of the apparent inconsistency between local and scientific knowledge. For example, intensive systems may support more effective management (e.g., appropriate and timely decision-making), even though they do not necessarily enhance specific ecological processes (i.e., plant and animal production; Briske et al. 2011). The intensive rotational grazing debate further underscores the need for knowledge co-production by managers and scientists and to document management decisions of landowners that contribute to the successes and failures of conservations practices.

\section{Conclusions}

A comprehensive interpretation of the rangeland CEAP synthesis indicates that existing USDA-NRCS conservation practices standards are insufficiently designed to support efficient, cost-effective, and accountable conservation programs. As currently structured, these standards are uncoupled from scientific information, relevant USDA databases, and most importantly, knowledge of environmental outcomes originating from conservation practices which is an explicit goal of CEAP and recent Farm Bills. We recommend that these conservation programs be restructured to establish a "Conservation Programs Assessment Network" to provide a more comprehensive and integrated platform to support evidence-based conservation. The focal point of this network would be collaborative monitoring of conservation practice outcomes among landowners, agency personnel, and scientists to establish the missing information feedback loops between conservation practices and their agricultural and environmental outcomes. This network would provide the capacity for accessing, archiving, and distributing conservation-relevant information to guide other conservation programs in appropriate ecoregions. Restructuring conservation programs as recommended will directly address two major challenges confronting USDA-NRCS conservation programs. First is the need for collaborative management to provide site specific information, learning, and accountability that has been requested by CEAP. Second, it will further advance efforts to balance delivery of agricultural production and environmental quality goals by documenting the trade-offs that exist among them in conservation programs. Concerns about the need for knowledge exchange and the mismatch between scientific evidence and conservation recommendations are not confined to the USA (e.g., Ison and Russell 2000, Wolfgramm et al. 2015). The recommendations presented here may promote development of useable knowledge by providing an approach for increasing knowledge exchange and coproduction among natural resource management agencies and research organizations worldwide.

\section{ACKNOWLedgments}

We thank all the scientists, USDA partners, and external reviewers for their contributions to the rangeland CEAP synthesis, and especially Dr. L. W. Jolley who provided leadership on behalf of USDA-NRCS. L. Jolley, P. Shaver, and S. A. Wolf provided constructive comments on earlier drafts of the manuscript. USDA-NRCS sponsored rangeland CEAP from which this assessment was derived. Two anonymous reviewers provided insightful comments that greatly improved the manuscript. All authors have directly contributed to data assessment, interpretation and writing of this manuscript, in their specific areas of expertise.

\section{Literature Cited}

Batie, S. S. 2009. Green payments and the US Farm Bill: information and policy challenges. Frontiers in Ecology and the Environment 7:380-388.

Bestelmeyer, B. T., J. R. Brown, S. D. Fuhlendorf, G. A. Fults, and X. B. Wu. 2011. A landscape approach to rangeland conservation practices. Pages 337-370 in D. D. Briske, editor. Conservation benefits of rangeland practices: assessment, recommendations, and knowledge gaps. Allen Press, Lawrence, Kansas, USA.

Bohensky, E. L., and Y. Maru. 2011. Indigenous knowledge, science, and resilience: What have we learned from a decade of international literature on "integration"? Ecology and Society 16:6.

Briske, D. D., editor. 2011. Conservation benefits of rangeland practices: assessment, recommendations, and knowledge gaps. Pages 429. Allen Press, Lawrence, Kansas, USA.

Briske, D. D., B. T. Bestelmeyer, T. K. Stringham, and P. L. Shaver. 2008. Recommendations for development of resilience-based state-and-transition models. Rangeland Ecology and Management 61:359-367. 
Briske, D. D., N. Sayre, L. Huntsinger, M. Fernandez-Gimenez, B. Budd, and J. D. Derner. 2011. Origins, persistence, and resolution of the rotational grazing debate. Rangeland Ecology and Management 64:325-334.

Bureau of Land Management (BLM). 2010. Rangeland interagency ecological site manual. BLM Manual 1734-1, Washington, D.C., USA.

Cain, Z., and S. Lovejoy. 2004. History and outlook for farm bill conservation programs. Choices 4th Quarter: 37-42.

Chan, K. M., A. M. R. Shaw, D. R. Cameron, E. C. Underwood, and G. C. Daily. 2006. Conservation planning for ecosystem services. PLoS Biology 4:e379.

Cook, C. N., M. B. Mascia, M. W. Schwartz, H. P. Possingham, and R. A. Fuller. 2013. Achieving conservation science that bridges the knowledge-action boundary. Conservation Biology 27:669-678.

Cundill, G. C., and C. Fabricius. 2009. Monitoring in adaptive co-management: toward a learning based approach. Journal of Environmental Management 90:3205-3211.

Desmarais, B. A., and J. A. Hird. 2014. Public policy's bibliography: the use of research in US regulatory impact analyses. Regulation and Governance 8:497-510.

Dilling, L., and M. C. Lemos. 2011. Creating usable science: opportunities and constraints for climate knowledge use and their implication for science policy. Global Environmental Change 21:680-689.

Duke, J. M., S. J. Dundas, and K. D. Messer. 2013. Costeffective conservation planning: lessons from economics. Journal of Environmental Management 125:126-133.

Duriancik, L. F., et al. 2008. The first five years of the conservation effects assessment project. Journal of Soil and Water Conservation 63:185-197.

Fairfax, S. K., and L. Fortmann. 1990. American forestry professionalism in the third world: some preliminary observations. Population and Environment 11:259-272.

Fernandez-Gimenez, M. E., S. J. McClaran, and G. Ruyle. 2005. Arizona permittee and land management agency employee attitudes toward rangeland monitoring by permittees. Rangeland Ecology and Management 58:344-351.

Ferraro, P. J., and S. K. Pattanayak. 2006. Money for nothing? A call for empirical evaluation of biodiversity conservation investment. PLoS Biology 4:0482-0488.

Fleischman, F., and D. D. Briske. 2016. Professional ecological knowledge: an unrecognized knowledge domain within natural resource management. Ecology and Society $21: 32$.

Gibbons, J. M., E. Nicholson, E. J. Milner-Gulland, and J. P. G. Jones. 2011. Should payments for biodiversity conservation be based on action or results? Journal of Applied Ecology 48:1218-1226.

Gold, A. J., et al. 2013. Advancing water resource management in agricultural, rural, and urbanizing watersheds: why landgrant universities matter. Journal of Soil and Water Conservation 68:337-348.

Head, B. W. 2015. Toward more "evidence-informed" policy making? Public Administration Review 76:472-484.

Herrick, J. E., J. W. Van Zee, K. M. Havstad, L. M. Burkett, and W. G. Whitford. 2005. Monitoring manual for grassland, shrubland and savanna ecosystems, Vol 1: quick start. University of Arizona Press, Tuscon, Arizona, USA.

Herrick, J. E., B. T. Bestelmeyer, S. Archer, A. J. Tugel, and J. R. Brown. 2006. An integrated framework for sciencebased arid land management. Journal of Arid Environments 65:319-335.

Holling, C. S., and G. K. Meffe. 1996. Command and control and the pathology of natural resource management. Conservation Biology 10:328-337.
Holmes, J., and R. Clark. 2008. Enhancing the use of science in environmental policy-making and regulation. Environmental Science and Policy 11:702-711.

Ison, R., and D. Russell. 2000. Agricultural extension and rural development: breaking out of knowledge transfer traditions. Cambridge University Press, Cambridge, UK.

Karl, J. W., J. E. Herrick, and D. W. Browning. 2012. A strategy for rangeland management based on the best available knowledge and information. Rangeland Ecology and Management 65:638-646.

Knapp, C. N., and M. E. Fernandez-Gimenez. 2009. Knowledge in practice: documenting rancher local knowledge in northwest Colorado. Rangeland Ecology and Management 62:500-509.

Lawton, J. H. 2007. Ecology, politics and policy. Journal of Applied Ecology 44:461-474.

Leopold, A. 1934. Conservation economics. Journal of Forestry 32:537-544.

Lindenmayer, D. B., M. P. Piggott, and B. A. Wintle. 2013. Counting the books while the library burns: why conservation monitoring programs need an action plan. Frontiers in Ecology and the Environment 11:549-555.

Ludwig, D. 2001. The era of management is over. Ecosystems 4:758-764.

MacMynowski, D. P. 2007. Pausing at the brink of interdisciplinary: power and knowledge at the meeting of social and biophysical science. Ecology and Society 12:20.

McDonald-Madden, E., et al. 2010. Monitoring does not always count. Trends in Ecology and Evolution 25:547-550.

National Sustainable Agricultural Coalition (NSAC). 2014a. Farm Bill http://sustainableagriculture.net/our-work/cam paigns/fbcampaign/what-is-the-farm-bill/

National Sustainable Agricultural Coalition (NSAC). $2014 b$. EQIP http://sustainableagriculture.net/publications./grass rootsguide/conservation-environment/environmental-qua lity-incentives-program/

Neugarten, R. A., S. A. Wolf, R. C. Stedman, and T. H. Tear. 2011. Integrating ecological and socioeconomic monitoring of working forests. BioScience 61:631-637.

Pouyat, R. V., et al. 2010. The role of federal agencies in the application of scientific knowledge. Frontiers in Ecology and the Environment 8:322-328.

Pullin, A. S., T. M. Knight, D. A. Stone, and K. Charman. 2003. Do conservation managers use scientific evidence to support their decision-making? Biological Conservation 119: 245-252.

Raymond, C. M., I. Fazey, M. S. Reed, L. C. Stringer, G. M. Robinson, and A. C. Evely. 2010. Integrating local and scientific knowledge for environmental management. Journal of Environmental Management 91:1766-1777.

Robinson, J. G. 2006. Conservation biology and real-world conservation. Conservation Biology 20:658-669.

Roche, L. M., T. K. Schohr, J. D. Derner, M. N. Lubell, B. B. Cutts, E. Kachergis, V. T. Eviner, and K. W. Tate. 2015. Sustaining working rangelands: insights from rancher decision making. Rangeland Ecology and Management 68: 383-389.

Roux, D. J., K. H. Rogers, H. C. Biggs, P. J. Ashton, and A. Sergeant. 2006. Bridging the science-management divide: moving from unidirectional knowledge transfer to knowledge interfacing and sharing. Ecology and Society 11:4.

Sayre, N., W. deBuys, B. Bestelmeyer, and K. Havstad. 2012. 'The Range Problem' after a century of rangeland science: new research themes for altered landscapes. Rangeland Ecology and Management 65:545-552.

Smith, K. R. 2006. Public payments for environmental services from agriculture: precedents and possibilities. American Journal of Agricultural Economics 88:1167-1173. 
Stafford Smith, D. M., et al. 2007. Learning from episodes of degradation and recovery in variable Australian rangelands. Proceedings of the National Academy of Sciences USA 104:20690-20695.

Sutherland, W. J., and R. P. Freckleton. 2012. Making predictive ecology more relevant to policy makers and practitioners. Philosophical Transactions of the Royal Society B 367: 322-330.

USDA NRCS Conservation Practices http://www.nrcs.usda. gov/wps/portal/nrcs/detailfull/national/technical/cp/ncps/ ?cid=nrcs143_026849.

Weichselgartner, J., and R. Kasperson. 2010. Barriers in the science-policy-practice interface: toward a knowledge-action- system in global environmental change research. Global Environmental Change 20:266-277.

Whitmer, A., et al. 2010. The engaged university: providing a platform for research that transforms society. Frontiers in Ecology and the Environment 8:314-321.

Wolfgramm, B., J. Shigaeva, and C. Dear. 2015. The researchaction interface in sustainable land management in Kyrgyzstan and Tajikistan: challenges and recommendations. Land Degradation and Development 26:480-490.

Woods, S. R., and G. B. Ruyle. 2015. Informal rangeland monitoring and its importance to conservation in a U.S. ranching community. Rangeland Ecology and Management 68: 390-401. 